\title{
DOCUMENTOS DEL SIGLO XVIII REFERENTES A LA PROVINCIA DE LOS PASTOS: PROBLEMAS DE INTERPRETACION
}


A pesar de ser un área poco favorecida por las visitas de virreyes, oidores y cronistas en general, contamos con suficientes versiones de la vida local y regional como para esbozar un panorama general del área. Citaré las fuentes más generales, para revisar luego las que hablan de la provincia en particular. Comenzaré con la crónica de Joseph de Acosta, "Historia natural y moral de las Indias", (1540-1600), quien de una manera muy amplia habla de la organización social de los indígenas americanos, específicamente del reino de Perú:

primeramente, en el tiempo antiguo, en el Pirú no habia reino ni señor a quien todos obedeciesen, mas eran behetrias y comunidades como lo es hoy dia el reino de Chile y han sido cuasi todos los que han conquistado españoles en aquellas Indias Occidentales, excepto el reino de Mexico, para lo cual es de saber que se han hellado tres generos de gobierno y vida en los Indios, el primero y principal y mejor ha sido de reino y monarquia, como fue el de los ingas y el de Montezuma, aunque estos eran en mucha parte tiránicos. El 2o. es de behetrias o comunidades. donde se gobiernan por consejo de muchos y son como consejos. Estos en tiempo de guerra eligen un capitan a quien toda una nación o provincia obedece. En tiempo de paz, cada pueblo o congregación se rige por si y tiene algunos principalejos a quienes respeta el vulgo y cuando mucho, juntanse algunos de estos a negociar en lo que les parece de importancia, a ver lo que les conviene. El 3er. genero de gobierno es totalmente bárbaro y son indios sin ley, ni rey, ni asiento, sino que andan en manadas como fieras y sal. vajes. Cuanto yo he podido comprender, los primeros moradores de estas indias fueron de este genero.

Esta relación de Acosta por ser tan general y simplista no nos es de gran ayuda, ya que el grupo que nos ocupa parece presentar problemas en el estudio de su organización social: se trata de un enclave de gente que ocupa la parte más septentrional del Imperio Incaico, que presenta rasgos bastante contradictorios y que si tratáramos de clasificarlo en cualquiera de las tres categorías de Acosta pecariamos de unilateralidad.
De las Casas, quien creíamos, se había olvidado del área de la cultura Pasto, nos dice:

Las tierras y los reinos que los nuestros entienden por el Perú, son todo lo que se comprende desde la provincia de Quito donde fundaron una villa que dijeron San Francisco y que parte limites y términos con la provincia que dijimos de Pasto, hasta la villa de La Plata con los suyos..

Al llegar a la provincia de Pasto, que es la más próxima al Perú, la describe así:

A las gentes de alli siguen otras que son muchas, llamadas Pastos; ni comen carne humana, ni ofrecen sacrificios de hombres, ni por memoria se siente cosa que huela al pecado nefando. $\mathrm{Y}$ por que de estas provincias no tenemos mucha noticia mas de la dicha, que es cuasi general y es bien ahorrar tiempo... (Madrid, 1909).

Otro cronista que nos dice algo de los Pasto, sin diferenciarlos de los Quillacinga, es Antonio de Herrera en su "Descripción de las Indias Occidentales del mar Oceano" (Madrid, 1730):

La ciudad de San Juan de Pasto, dicha asi porque es tierra de muchos pastos, está cincuenta leguas de Popayan, como al sudeste y otras tantas de el Quito, como al nordeste y en un grado de la equinoccial, diocesis de Quito, en buena tierra, de buen temple y abundosa de maiz y otros mantenimientos, con minas de oro, en su comarca 240 indios de encomienda, que no son caribes, sino de malas cataduras, sucios y simples: no tuvieron idolos en su gentilidad; creian que despues de muertos habian de ir a vivir a partes mas alegres.

El cronista por excelencia para la provincia de los Pastos, es Pedro Cieza de León, quien publicó su obra, "La crónica del Perú", a los alrededores de 1550; él hace un análisis más detallado de estos indios y comienza por mencionar los principales pueblos de los Pasto: "Ascual, Mallama, Tucurres, Zapuys, Iles, Gualtmatan, Funes, Chapal, Males, Ipiales, Pupiales, Turca y Cumba. Todos estos pueblos y caciques tenían y tienen por nombre Pastos". Los documentos del siglo XVIII confirman esto que Cieza menciona, que los caciques toman el nombre de sus pueblos; continúa Cieza:

Las costumbres destos indios Quillacingas ni Pastos, no conforman unos con otros, porque los Pasto no comen carne humana cuando pelean con los españoles o con ellos mismos. Las armas que tienén son piedras en las manos y palos a manera de callados y algunos tienen lanzas mal hechas y pocas; es gente de poco ánimo. Los indios de lustre y principales se tratan algo bien; la demás gente es de ruines cataduras y peores gestos, asi ellos como sus mujeres, y muy sucios todos; gente simple y de poca malicia. Así ellos como todos los demas que se han pasado son tan poco asquerosos, que cuando se espulgan se comen los piojos como si fuesen piñones, y los vasos en que comen y ollas donde guisan sus manjares no están mucho tiempo en los lavar y limpiar. No tienen creencias ni se les han visto idolos, salvo que ellos creen que despues de muertos han de tornar a vivir en otras partes alegres y muy deleitosas para ellos. 
Cieza habla aquí de cierta diferencia social entre los Pasto al mencionar a los indios de lustre y principales y a la "demás gente" situación que encontraremos más adelante en los documentos del siglo XVIII, en donde se destaca, en las numeraciones de indios, al cacique y su familia del resto de los integrantes de la comunidad.

Cieza de León es el primero en destacar las diferencias que existían entre las costumbres de los Pasto y las de los Quillacinga. Más adelante, en 1595, (según transcripción de F. Cionzales Suares), el obispo Solís convocó en Quito al Sínodo en que se ordena que la lengua quechua se hable en toda la diócesis y que el mercedario Fra forme un vocabulario de la lengua de los Pasto y los presbíteros Andrés Moreno de Zúniga y Diego Bermúdez, otro de la de los Quillacinga, dando a entender que hablaban diferentes lenguas. El cosmógrafo y cronista mayor de Indias, Juan López de Velazco (1574), dice de la provincia:

Los indios de su jurisdicción se reparten en cuatro provincias; una de ellas se llama de los Pastos, tierra fría y de gente mal vestida y miserable, en que hay abundancia de algodón y algunas ovejas del Perú y miserable, dos y perdices, mucho malz y papas y de oro que hasta ahora se hayan descubierto; las martes, sin minas moradas de los indios hios de paja.

En 1586, publica Miguel Cabello Balboa su "Miscelánea Antártica" muy generosa en datos sobre la Costa Pacífica de Colombia, desde el puerto de Buenaventura hacia el sur, pero escueta en lo que se refiere a la provincia de los Pastos, a pesar de haber sido cura de Funes, pueblo de Pastos. Hablando de las incursiones de los incas en la parte de la provincia que corresponde a la actual provincia del Carchi en el Ecuador, ce:

Por sus jornadas llegaron estas gentes del inga a los confines y términos de una tierra asperísima fría montuosa y de pocas y mal puestas poblaciones, $y$ al cabo de algunos trabajos que se les ofrecieron comenzaron a ha. llar pueblos con sola la gente inútil y sin provecho, asl como viejos, viejas, niños y muchachos de poca edad y algunos indiezuelos débiles y de poca cuenta, y de estos tuvieron rastro que algunas jorne la población principal y de quien se debí las guías y lenguas necesarias, caminaron hasta dar con blo del señor de necesarias, caminaron hasta dar con el asiento y pue de señor de aquella provincia donde vieron sus humildes casas cercadas de gran población..

Nuevamente aparecen los Pasto como gente pobre, de poco interés y de cultura rudimentaria.

Fray Jerónimo de Escobar, en su "Descripción de la Provincia de Popayán", (en la versión corregida por Juan Friede), escrita a finales de siglo XVI, hace un recuento muy detallado de los pueblos de la provincia de Popayán, del cual extraigo lo referente a los Pasto:

... y como son bárbaros, cuanto se les ha enseñado en diez años, se pierde en diez dias; de más que estos dlas vacan en mil vicios que sen juntar todo el pueblo a que baile en la plaza con grandes tinajas con cerveza que es el vino con que ellos se emborrachan y es ordinario entre ellos, en ausencia de los sacerdotes evangélicos, ocuparse en esto y dura cada baile dos dias y tres sin dormir y en este tiempo adoran idolos y hacen otras muchas ofrendas al demonio, estando borrachos se matan unos a otros y hacen otras torpezas indignas de decir a V. Alteza, porque el padre ni guarda honestidad con la hija, ni el hermano con la hermana y así hacen incestos espantosos.

Primera mención de incesto entre los Pasto y de adoración de ídolos, relato que contradice la versión de Cieza.

En 1592, Francisco de Anuncibay rinde un informe a la corona sobre la población indígena de la provincia de Popayán; aunque tiende a hacer generalizaciones sobre las costumbres de los indígenas de toda la provincia, y exagera con fines políticos, su versión no deja de ser interesante:

Esta tierra fue habitada de poca gente que tenia en si muchas lenguas, no tenian Rey ni Ley ni superstición alguna, y vivian cada uno en su casa (...) y que para cazar y para se defender se juntaban, y para sus bailes y borracheras y casamientos (...) el que más comida tenia o mas valien te se mostraba era electo por aquella vez por cabeza y capitan y duraba segun lo hacía y le sucedía. Vivian por behetria, porque cada río los apartaba en lengua, en costumbres, en traje y condiciones y bandos (...) sus armas eran lanzas, largas macanas como espadas, algunos arcos y mas dardos tostadas las puntas. Entre si fueron y son belicosos. (...) Tuvieron mucho oro... pero no para comprar ni vender porque nunca conocieron precio y ni contratos de emptios (compra), ni vendieron quedandose en puros terminos de permuta. Son indios robustos, carnudos, morenos de ojo negros, holgazanes, bebedores y grandes cazadores.

\section{Más adelante dice:}

Es la tierra fértil de maiz que se siembra en los montes en rozas de fuego. No tuvieron plata, ni cobre ni hierro; hay ciervos y dantas y zorras y conejos, perdices y paujies.

Estas son las noticias que sobre los Pasto tenemos, escritas en el siglo XVI. Se trata, pues, a grandes rasgos, de behetrias, para lo cual es conveniente recordar qué entendían los cronistas españoles por este término: se designaba en España con el nombre de behetrias a los burgos libres cuyos habitantes tenían el privilegio de elegir su señor, sea entre los miembros de una familia determinada (behetria de linaje), sea a su antojo (behetria de mar a mar); esta palabra significa pues, que los in dios no obedecían sino a jefes elegidos por sí mismos (Louis Baudin 1972). No se mencionan en estos documentos tempranos datos referentes a tenencia de tierra, ni a territorialidad; Fray Jerónimo de Escobar hace alusión a la endogamia, rasgo que contradicen los documentos del siglo XVIII, los cuales hablan muy claramente de exogamia; todas las demás versiones parecen estar de acuerdo al afirmar que los Pasto eran cultivadores de tubérculos andinos, de maíz y buenos cazadores. 
Se habla mucho de la conquista incaica del territorio nariñense y con el fin de ilustrar un poco este punto, citaré las versiones más conocidas, como es la de Cieza de León, quien al respecto afirma: "En estas regiones de los pastos hay otro rio algo grande que se llama Angasmayo, que es hasta donde llegó el rey Huaina Capac, hijo del gran capitan Topainga Yupangue, rey del Cuzco". El inca Garcilazo, fija los límites extremos de las conquistas de sus antepasados en el río Maule en Chile y en el río Angasmayo, en el suroeste de Colombia (S.E. Ortiz, 1960). Acosta nos dice: "su principio y origen (de los incas) fue del valle del Cuzco y poco a poco fueron conquistando la tierra que llamamos Pirú, pasando Quitu hasta el rio Pasto, hacia el norte...".

Jaime Arroyo, en su "Historia de la Gobernación de Popayán", habla de la conquista incaica en los siguientes términos: “...a poca distancia al sur del Carchi, se halla Tulcán, último pueblo sometido por esta parte al dominio de los incas y en el cual opusieron los naturales alguna resistencia a Tapia, que fue luego vencida".

Citando a Sergio Elías Ortiz,

por lo que se sabe históricamente, de acuerdo con las relaciones de Garcilazo de la Vega, Montesinos, Francisco de Toledo, Sarmiento de Gamboa, Cabello de Balboa, Cieza de León y el padre Juan de Velazco, la conquisincaica hacia el norte de Quito fue muy tardía, principiada apenas a finales del siglo XV.

Todos los autores coinciden en designar al río Angasmayo (actual Guáitara) como frontera septentrional del Imperio, y solo algunos hablan de intrusiones más allá del mencionado río, como es el caso de Cabello Balboa; Cieza afirma enfáticamente sobre la mencionada conquista inca: “... pues tenian por conquista sin provecho la que hacian en la region de los pastos".

Acerca de la presencia de rasgos incaicos y de quechuismos en territorio nariñense, es prudente recordar que esta área del sur de Colombia fue conquistada y colonizada por españoles que venían de Quito, entre ellos Tapia, Añasco, Ampudia y Belalcázar, quienes se valieron de indios yanaconas traídos del sur para facilitar la colonización, los cuales eran utilizados como cargueros; estos indios se fueron estableciendo en las regiones conquistadas y no es extraño encontrar poblados de yanaconas en los pueblos de Túquerres, Cumbal, Ipiales y Pupiales (según documentos del Archivo Central del Cauca; ver Bibliografía), y en general a lo largo del camino Quito-Popayán. Es muy probable que sean estos yanaconas los que introducen una serie de rasgos de tipo incaico entre los pasto, aunque es evidente que ellos no representan el único contacto del área con los grupos de cultura avanzada de influencia incaica.

\section{DOCUMENTOS TARDIOS: NUMERACION DE INDIOS LLEVADA A CABO}

EN 1735

A) Los materiales empleados en la presente investigación, exceptuando fuentes de segunda y tercera mano son:

Documento 296 (Col. Civil I-7g Tomo 1o.) Archivo Central del Cauca

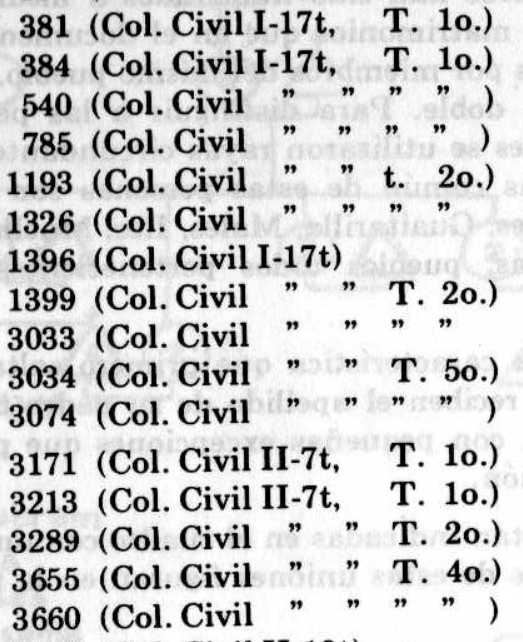

"

B) La base de la presente investigación es un documento, que aparece con la numeración 3660 en la columna que antecede, fechado en Ipiales en 1735, el cual, después de una serie de formalismos introductorios dice así:

de todos los pueblos pertenecientes a esta jurisdicción, asi de los pertenecientes a la corona real como de los anaconas... (ilegible)... Francisco Quistial y Agustin Yaguapaz, gobernadores actuales que por haberse muerto el cacique y no haber dejado sucesor se pone por caciqueza a Tomaza Actás Chapueram, como hija legítima de Florencio Martinez y Francisca Actás Chapueram, caciques principales que fueron deste dicho pueblo, nieActás Chap a de Francisco Chapueram y Maria Actás, bisneta de Lazaro Chapueram, todos caciques que fueron deste dicho pueblo y por haberse muerto el sucesor que lo fue Jose Patricio Garcia Carlosama Chapueram, quien estuvo reinando por tal cacique y no dejo sucesor, no se ha hallado otro de mejor derecho que la dicha Tomasa Actás por ser como hija legítima de los otros Florencio y Francisca y la mayor de Manuela y Jacinta Actás, las cuales estan casadas Manuela con un mestizo y Jacinta con Simón Mueses, cacique y cacica de los Anaconas por lo cual los naturales gobernadores principales han aclamado por tal su cacica a la dicha Tomasa Actás..

Después de lo cual se da comienzo a la numeración de indios, que por razones de espacio no es posible incluir aquí. El documento termina 
con el recuento de todos los miembros de la comunidad, los cuales están distribuidos en 10 aillos o parcialidades, cada parcialidad con su prin cipal mayor y dos gobernadores y un total de 1078 indígenas.

El cuadro que sigue a continuación está formado por la representación gráfica de todos los integrantes de la parcialidad o aillo de Ipiales, de la jurisdicción de Ipiales, sujeto a la caciqueza Tomasa Actás Chapueram.

Explicación del cuadro: Las familias aparecen numeradas del 1 al 34 los apellidos de sus miembros han sido numerados a medida que van a dos 1 a 33 . Los matrimonios que en el documento aparecen apareciendo, del 1 a 33 . Los matrimonios que en mismo pueblo, van unidos especifidos proen el cuadro con una línea doble. Para distinguir a las personas procedentes de otras comunidades se utilizaron rayas circundantes a manera de soles. La procedencia más común de estas personas son los pueblos de Mallama, Cumbal, Pupiales, Guaitarilla, Males, Iles, Muellamués, Carde Mallama, Cumbal, Pupiastén y Pueblos todos pertenecientes a la provincia de los pastos.

Analizando el cuadro, la característica que primero salta a la vista es el hecho de que los hijos reciben el apellido de su padre mientras las hijas reciben el de la madre, con pequeñas excepciones que pueden atribuirse a errores de la numeración.

Las uniones inestables están indicadas en el cuadro con una línea vertical oblicua doble, y los hijos de estas uniones figuran en la numeración como hijos naturales.

\section{Cacicazgo}

En el año de la numeración (1735) la caciqueza Tomasa Actás Chapueram tenía entre 58 y 60 años, "por ser mayor que su hermana María”, quien para esa fecha contaba con 56 años, es decir, había nacido en ría", quien para suadre tendría quizá 20 años, el cual a su vez habría naci1675 , cuando su padre tendría quiza 20 anos padre podría contar con 20 do a los alrededores de 1655 , época en que su padre podría contar con 20 años, lo que significa entonces que el abuelo de Tomasa Actás habría nacido hacia 1635, cuando a su vez el padre (bisabuelo de Tomasa) tendría 20 años, lo cual significa que don Lázaro Chapueram habría nacido a principios del siglo XVII. Para esta época, Ipiales ya era una encomienda española y doctrina de los frailes de Sto. Domingo y es posible que ya los clérigos hubieran "legalizado" algunos matrimonios indígenas y establecido ciertos cargos entre ellos. No sabemos si la genealogía de Tomasa Actás sea fiel a las leyes de herencia y parentesco indígenas o más bien esté reflejando instituciones coloniales hispánicas, el caso es que la susodicha, hereda el derecho al cacicazgo por "defecto de varon", al igual que su madre, y por ser nieta y bisnieta de caciques muertos. Su hermana que carlosama y su hermana menor está casada con el cacique de los Anaconas de Ipiales; tenemos aquí menor está casada con el cacique de los Anaconas de Ipiales, tenemos o par46 cialidades. ¿Con qué fin? El documento no menciona nada referen-
Familias integrantes del Ayllu de Jpiales - 1735
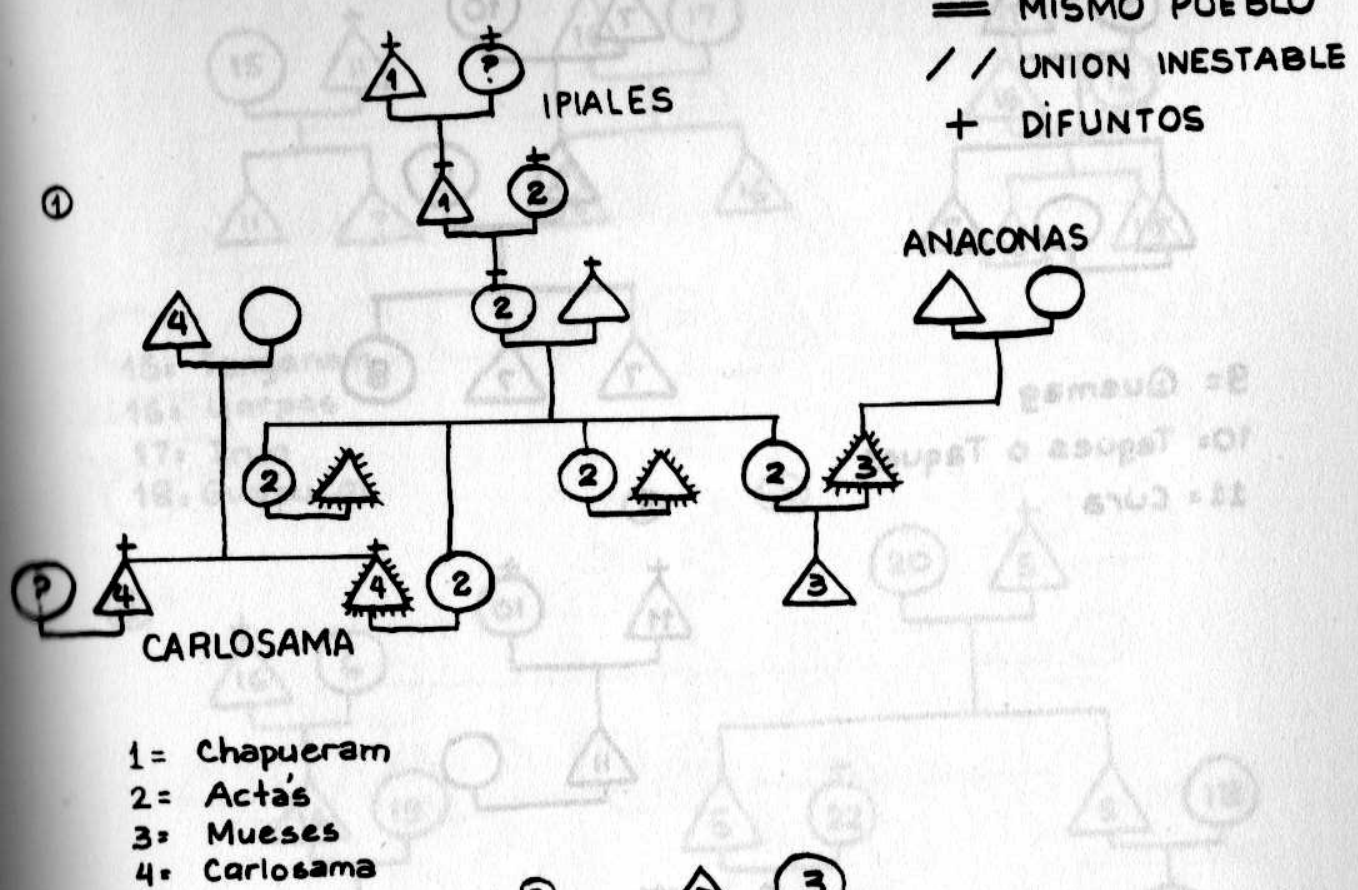

(2)

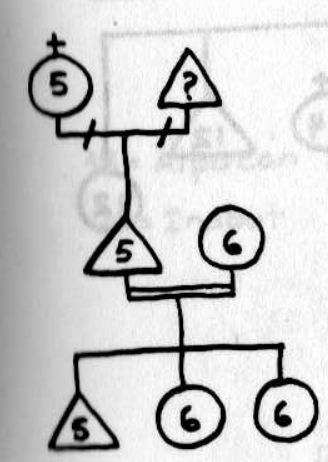

(3)
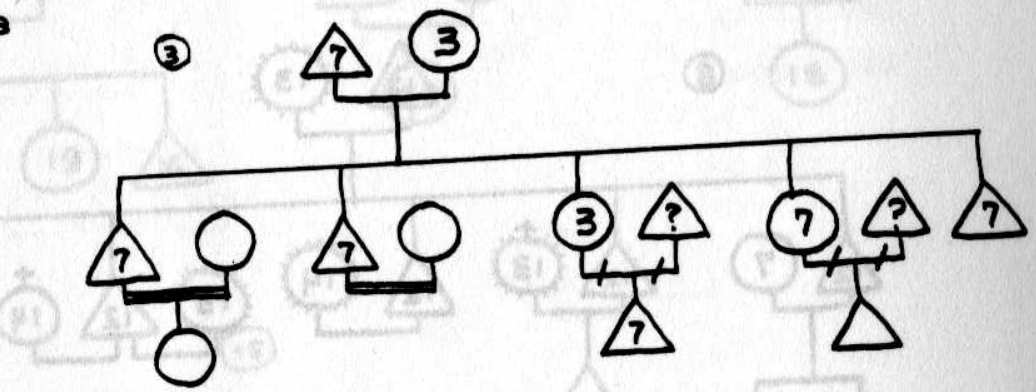

5. Pingchan

$6=$ Atis

7. guayal

$8=$ Pismag Pappas

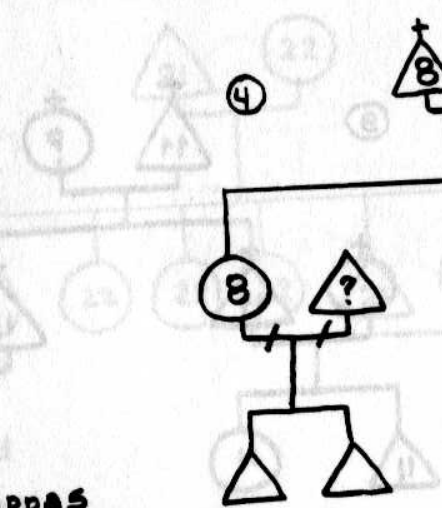

(7)
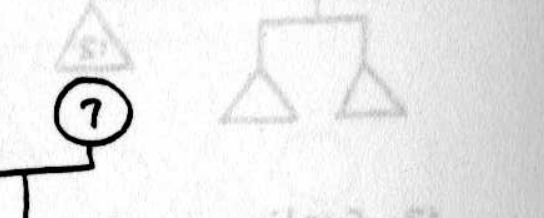


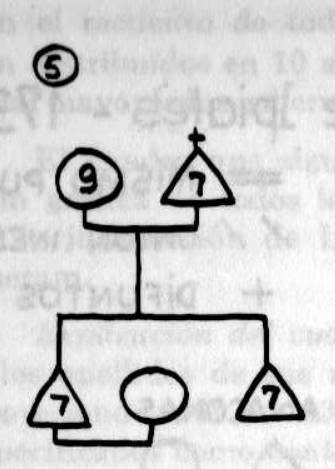

$9=$ Quemag

10: Teques o Taques

11 = cura

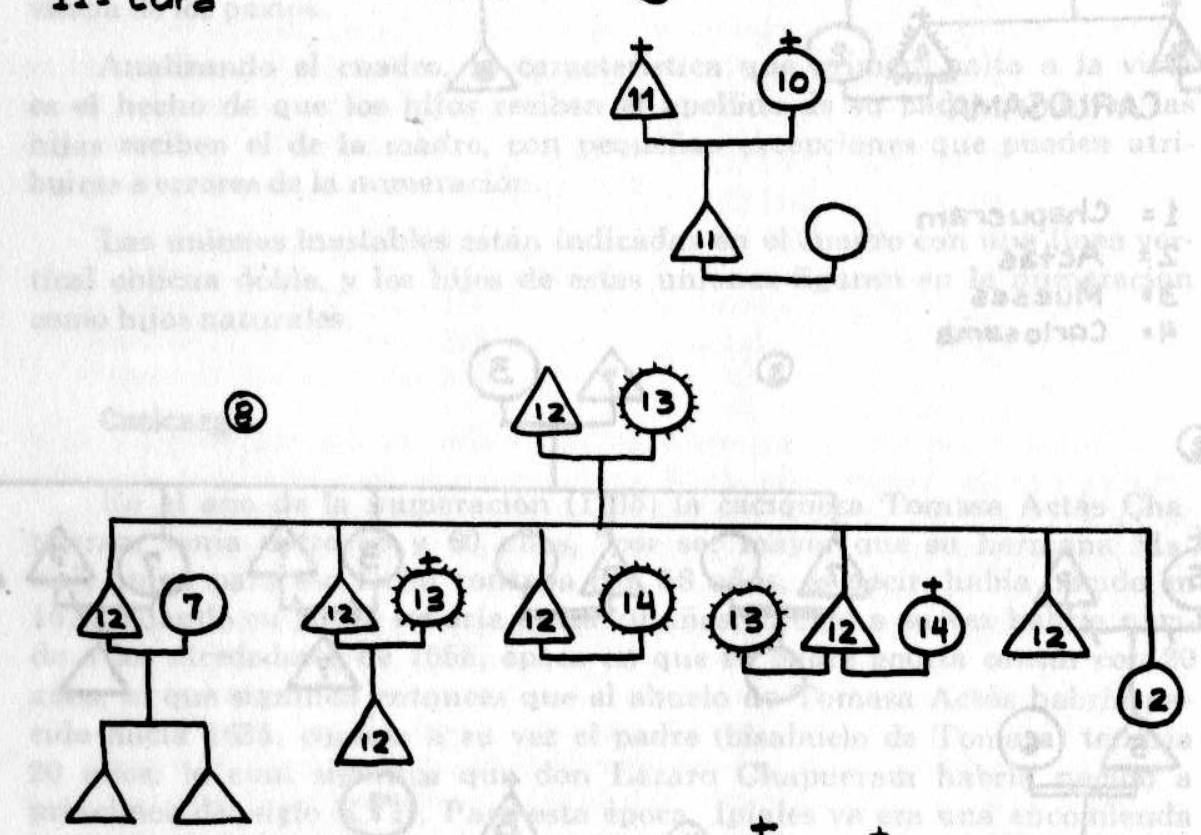

12: Cuatis

13: Pupiales

$14=$ Aqpas
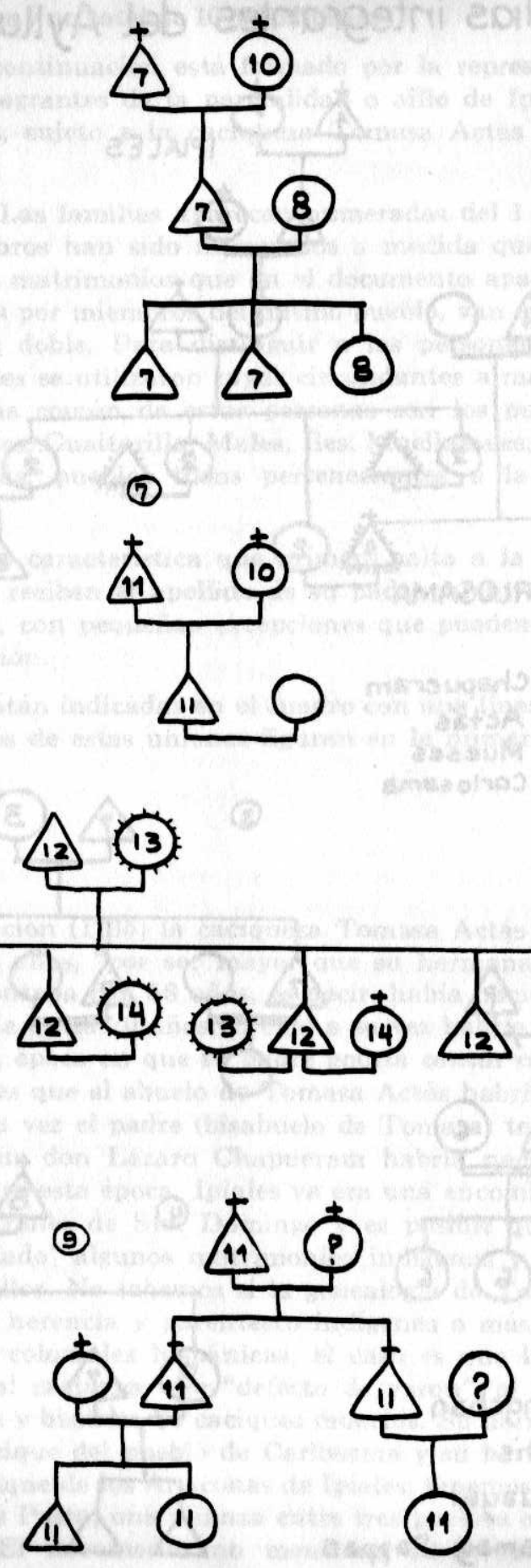

(1)

$$
14=\text { Aqpas }
$$

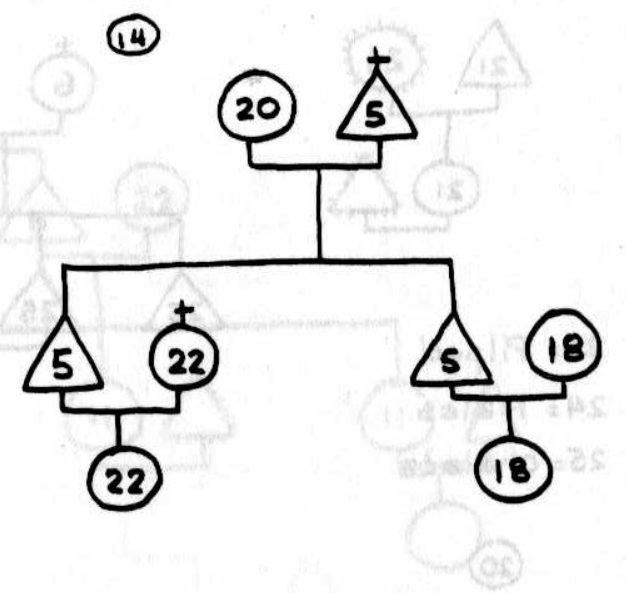

(16)

(41)

15: Tenganam

16: 4 arpas

17: Irua

18: Guapucal

(13)

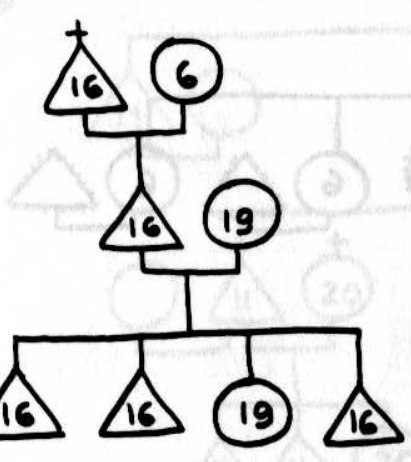

(12)

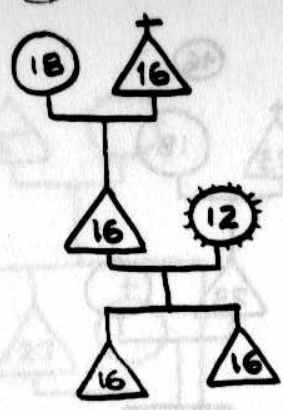

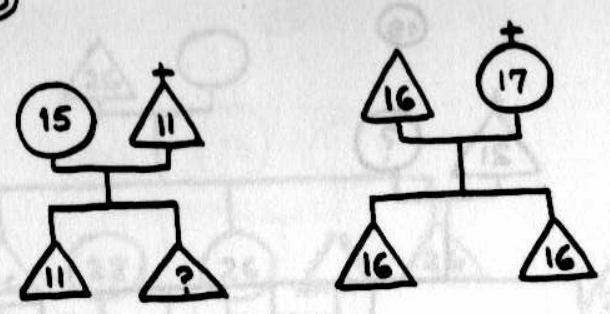




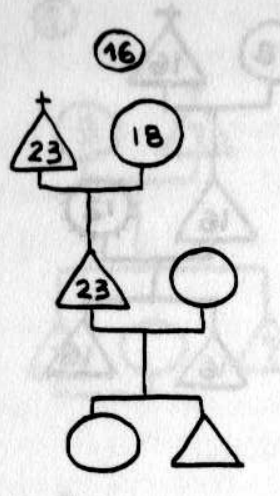

(17)

$$
\text { (21) }
$$

$23=$ Pilpud

$24=$ Males

$25=$ chalaca

(20)

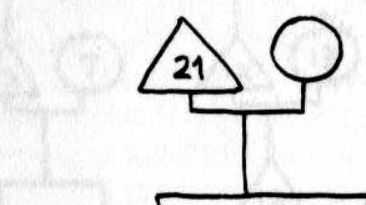

$C_{21} \bigcirc 3$ (3) (3) (3) (3) 0021
(211)

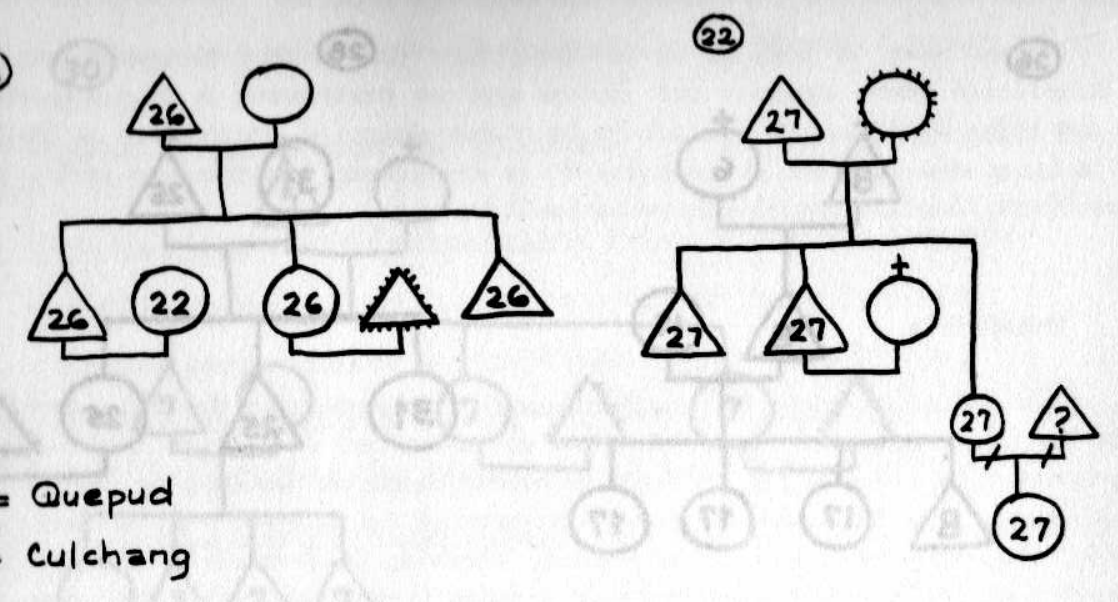

(27)

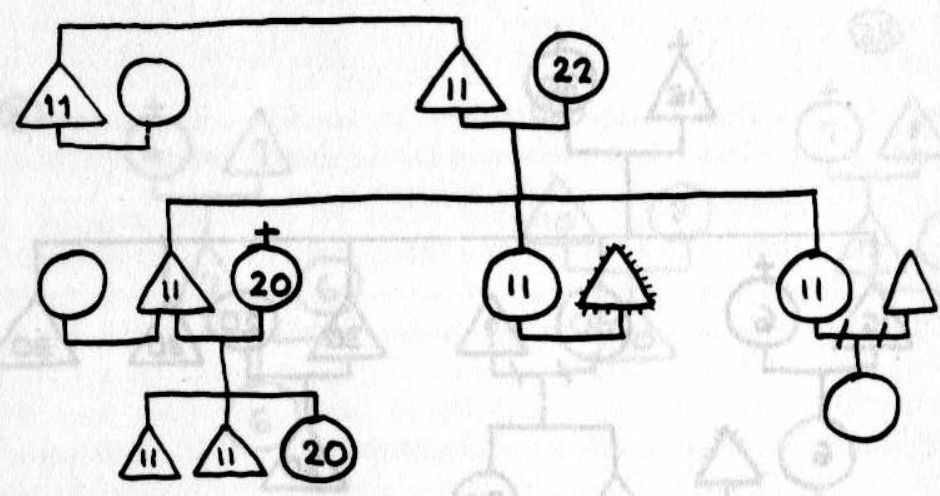

(2914)

(23)

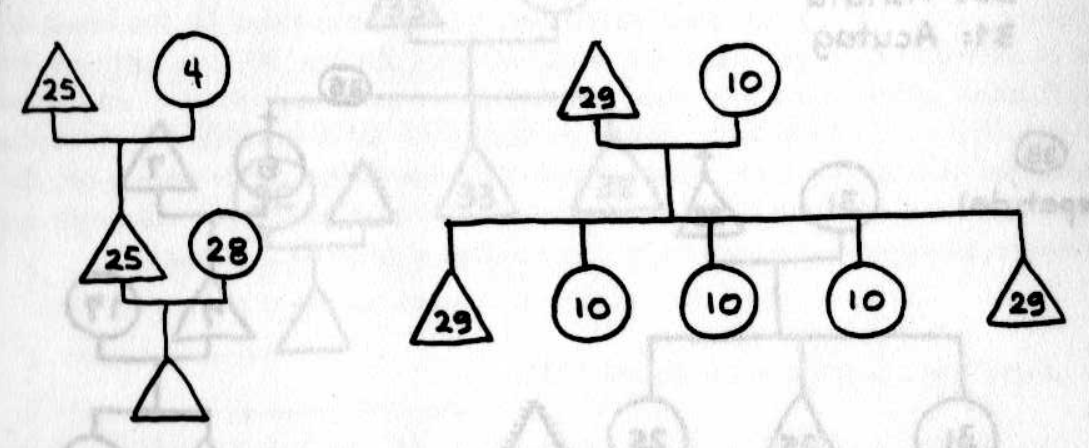


(20)

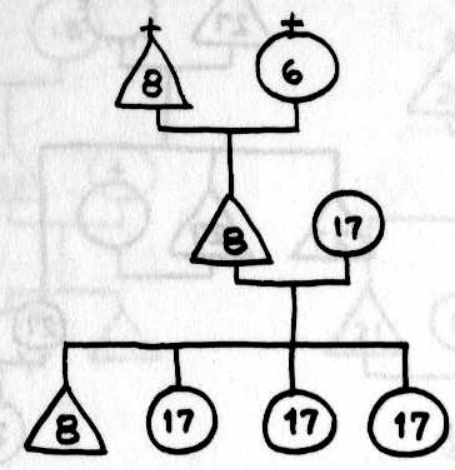

(27)

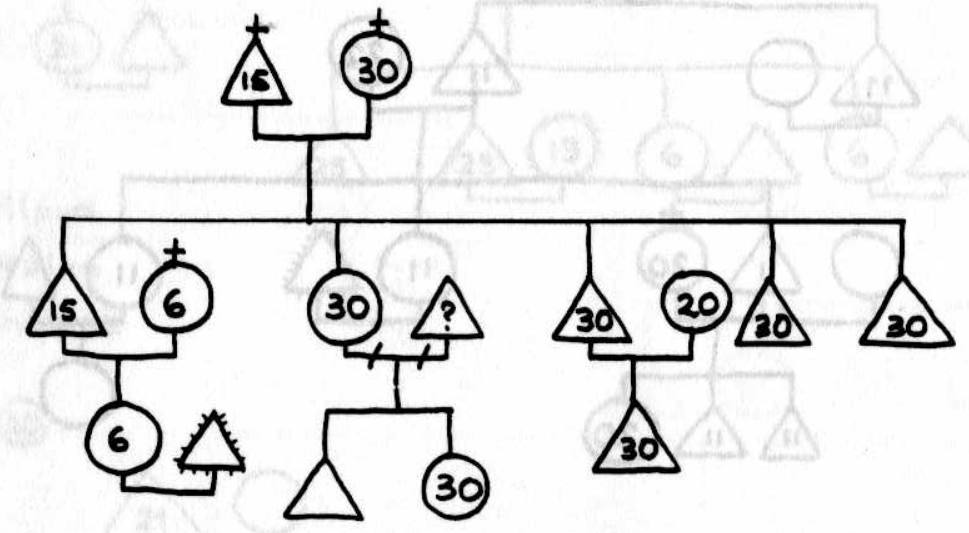

$30=$ Pistala

31: Acutag

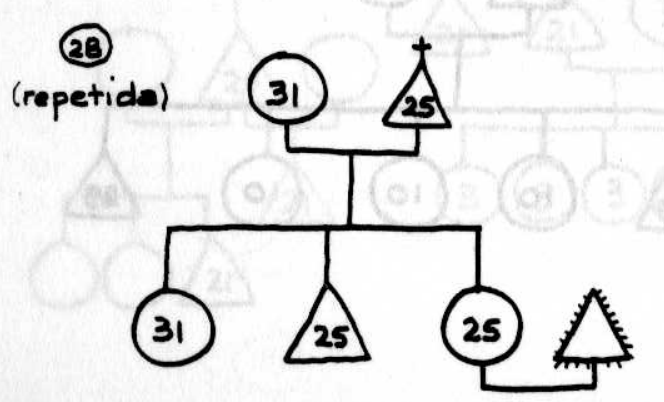

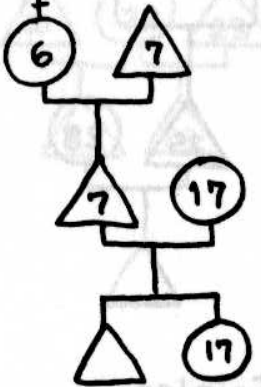

(20)

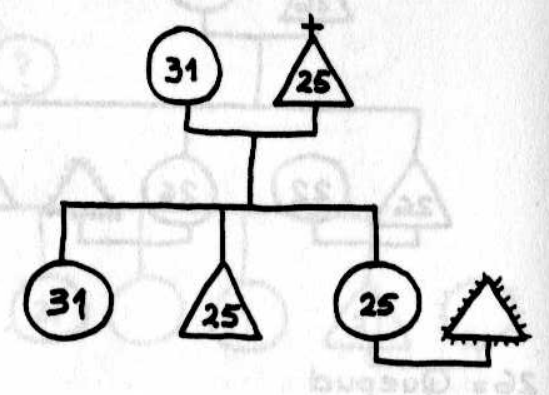

(3)

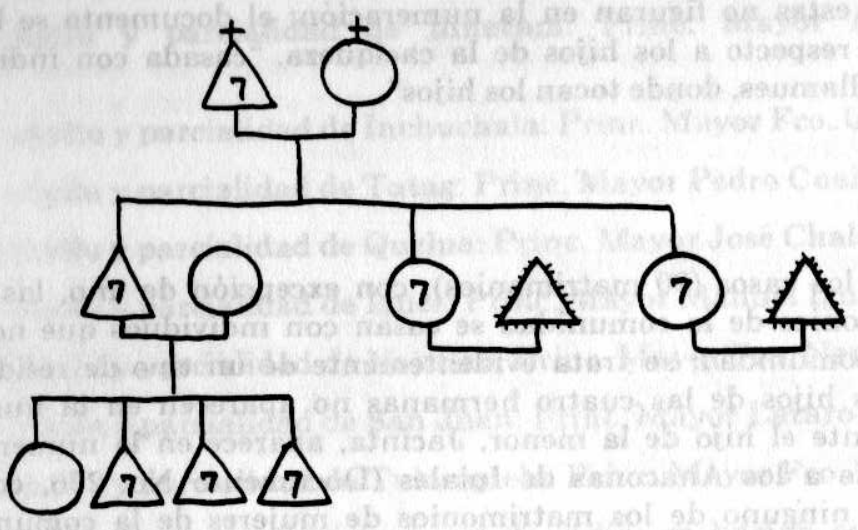

(31)
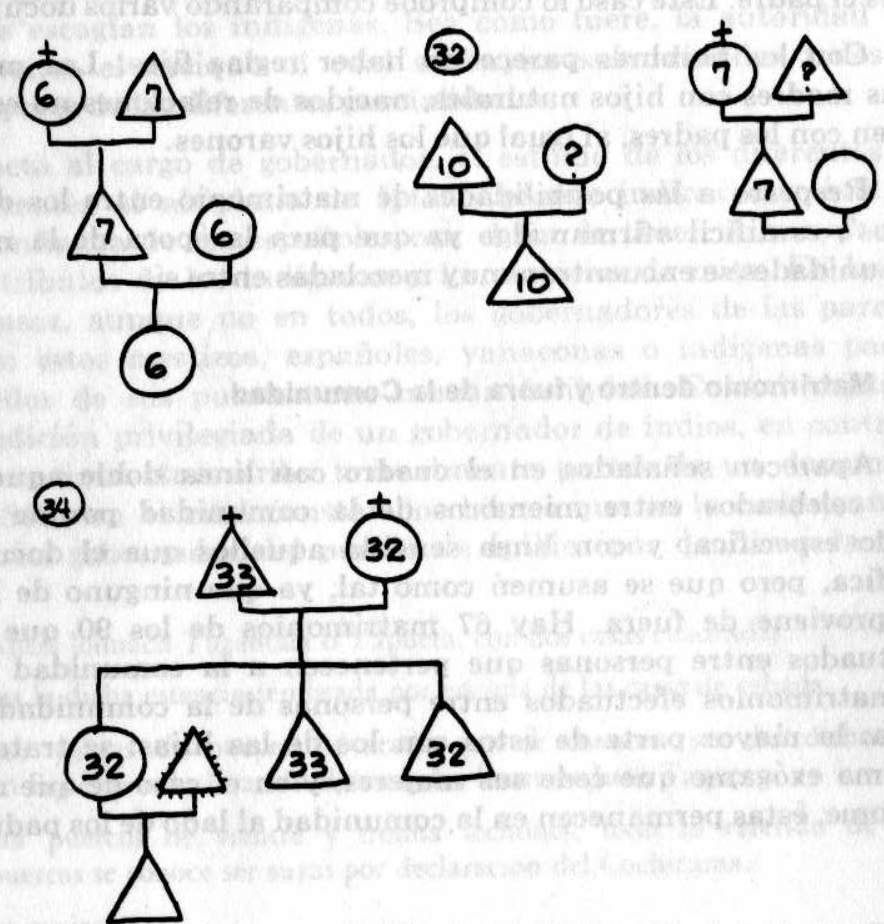
te a tenencia de tierras ni a propiedad territorial, aunque es muy posible que estas alianzas tengan relación con estos dos aspectos.

Analicemos la familia de la caciqueza: Las cuatro hermanas Actá Chapueram están casadas con indios que no pertenecen a la comunidad y los hijos de estas no figuran en la numeración; el documento se limita a aclarar con respecto a los hijos de la caciqueza, "casada con indio, de pueblo de Muellamues, donde tocan los hijos".

\section{Residencia}

En todos los casos (90 matrimonios), con excepción de uno, las hijas de los matrimonios de la comunidad se casan con individuos que no pertenecen a la comunidad; se trata evidentemente de un tipo de residencia patrilocal. Los hijos de las cuatro hermanas no aparecen en la numera ción; únicamente el hijo de la menor, Jacinta, aparece en la numeración correspondiente a los Anaconas de Ipiales (Documento No. 296, con fecha 1722); en ninguno de los matrimonios de mujeres de la comunidad, casadas con hombres de fuera, figuran hijos y ésto sucede así porque a los hijos les corresponde figurar en la numeración del pueblo de donde es el padre. Este caso lo comprobé comparando varios documentos.

Con los hombres parece no haber reglas fijas. Las mujeres solteras y las madres con hijos naturales, nacidos de relaciones no estables, permanecen con los padres, al igual que los hijos varones.

Respecto a las posibilidades de matrimonio entre los diferentes “apellidos", es difícil afirmar algo ya que para la época de la numeración las comunidades se encuentran muy mezcladas entre sí.

\section{Matrimonio dentro y fuera de la Comunidad}

Aparecen señalados en el cuadro con línea doble aquellos matrimonios celebrados entre miembros de la comunidad porque el documento así lo especifica, y con línea sencilla aquellos que el documento no pecifica, pero que se asumen como tal, ya que ninguno de los contrayentes proviene de fuera. Hay 67 matrimonios de los 90 que son en total, efectuados entre personas que pertenecen a la comunidad y únicamente 23 matrimonios efectuados entre personas de la comunidad con gente de fuera: la mayor parte de éstos son los de las hijas: se trata, pues, de un sistema exógamo que cede sus mujeres, y en el caso de que no haya quien las tome, éstas permanecen en la comunidad al lado de los padres.

\section{Estructura política del Ayllu de 1735}

En el documento estudiado, la jurisdicción de Ipiales, "desde el Guaitara hasta el río de Tulcan", está compuesta por 1078 indígenas, distribuidos en ayllus o parcialidades, como sigue:
-Ayllu y parcialidad de Ipiales: caciqua y principal mayor Tomasa Actás Chapuerám.

-Ayllu y parcialidad de Chalamag: Princ. Mayor Agustín Chala mag.

-Ayllu y parcialidad de Idnacam: Princ. Mayor Antonio Yandum.

-Ayllu y parcialidad de Inchuchala: Princ. Mayor Fco. Quamag.

-Ayllu y parcialidad de Tatag: Princ. Mayor Pedro Cuaiquier.

-Ayllu y parcialidad de Quelua: Princ. Mayor José Chalacán.

-Ayllu y parcialidad de Igués: Princ. Mayor Manuel Igués.

-Ayllu y parcialidad de Nayalab: Princ. Mayor Fco. Nayalab.

-Ayllu y parcialidad de San Juan: Princ. Mayor Lazaro Hezamag.

-Ayllu y parcialidad de Tulanquela: Princ. Mayor Fco. Tulanquela.

Sabemos que las numeraciones de indios se hacían con el objeto de separar e identificar a los indios útiles tributarios. Lo que es difícil precisar es si las autoridades de estas parcialidades eran impuestas por los españoles o las 'escogían los indígenas. Sea como fuere, la autoridad máxima la representa el cacique al cual se hayan subordinados todos los principales mayores de las diferentes parcialidades.

Con respecto al cargo de gobernador, el estudio de los diferentes documentos referentes al altiplano de Ipiales parece indicar que éste era un cargo de confianza de los españoles con el fin de tener un mayor control sobre los tributos de los indígenas y los servicios de mita. En la mayoría de los casos, aunque no en todos, los gobernadores de las parcialidades, ya sean estos mestizos, españoles, yanaconas o indígenas pastos, se ven removidos de sus puestos con mucha facilidad. Con el objeto de resaltar la condición privilegiada de un gobernador de indios, en contraste con la de un cacique, transcribo textualmente partes de un documento de 1671 (No. 540), en el cual constan los bienes que se le embargaron a Francisco Equés, gobernador del pueblo de Ipiales por deudas a la corona real:

1. Una estancia llamada Tuzantala o Yapueta, con dos casas cuadradas.

2. Mas tiena la dicha estancia sembrada por encima de las casas de cebada.

3. Mas doce yuntas de bueyes de arada que se conocen ser del dicho Francisco Equés por declaración de un indio llamado Juan Taques.

4. Cincuenta puercos de vientre y treinta lechones, todo lo referido de dichas puercas se conoce ser suyas por declaracion del Cochicama.

5. Mas diez ovejas.

6. Mas treinta cabras chicas y grandes.

7. Mas cincuenta fanegas de cebada

Mientras que en el testamento del cacique Cristóbal Cuatín del pueblo de Tuza, hecho en 1593, constan ser sus bienes 
1. Un peso de pesar oro con sus pesas, en su caja de hoja de lata.

2. Una cadenilla de alquimea.

3. Dos pares de limbiquiros de uso del Cuzco.

4. Dos caracoles

5. Dos mantas pintadas llamadas Quimnto Pacha y dos mantas de algodón y una camiseta de paño azul, ya raida y una camiseta pintada.

6. Una cazuelita de peltre y una cuchara de plata..

\section{Algo más sobre los Cacicazgos}

A continuación aparecen representados de manera esquemática, los cuatro cacicazgos de las cuatro aldeas estudiadas más detenidamente, a saber: Ipiales, Pupiales, Gualmatán y Putis. Las flechas indican el sentido en que se hereda el cacicazgo.

PUPIALES:
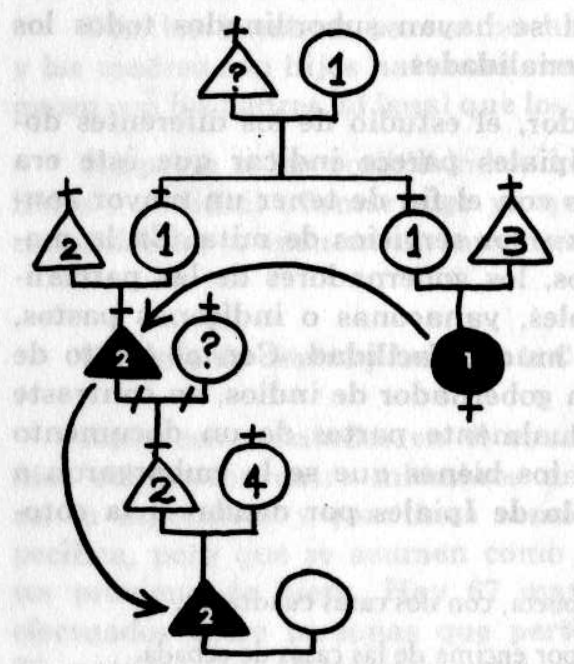

$1=$ Funes 2 = Taques

$3=$ Cuatis

$4=$ Tudnem
GUALMATAN:

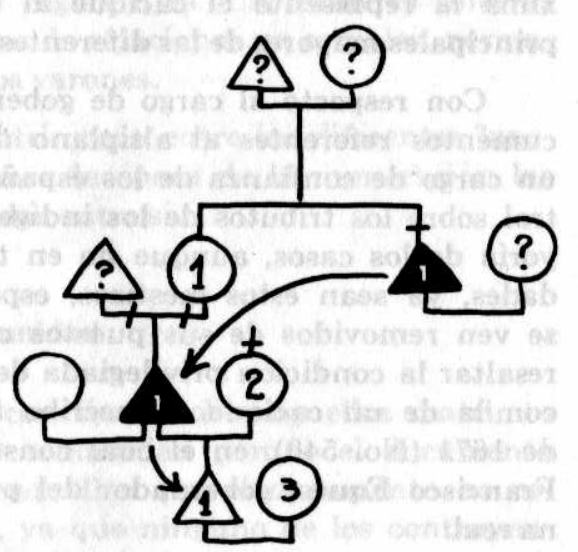

Nota: En negro aparecen los caciques. 


\section{EVOLUCION DE LA ENCOMIENDA EN EL ALTIPLANO DE IPIALES}

Planteado a grandes rasgos, el poblamiento de esta provincia de los Pastos se llevó a cabo de la siguiente forma:

Donde había un caserío indígena o un núcleo de población indígena dispersa pero considerable, los españoles establecen la encomienda; no hay residencia permanente de españoles en la localidad; éstos se hacen presentes (los encomenderos) cuando hay que hacer las cuentas de los tercios de Navidad y San Juan y cuando así lo exigen los asuntos tributarios:

Se funda el poblado español, con residencia permanente de españoles.

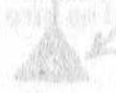

Aparecen el mestizaje, la Mita, los obrajes, las haciendas:

Alrededor de los poblados, se establecen - no geográficamente, pues éstas ya existían, sino como tributarias-, las diferentes parcialidades indígenas o "ayllus" (de los documentos del siglo XVIII), conocidas también como repartimientos de indios, teniendo entonces:

\section{$\downarrow$}

Las tenencias o jurisdicciones, - de Ipiales, por ejemplo- con sus diferentes parcialidades y pequeños caseríos de indígenas o núcleos de población dispersa. Finalmente estas parcialidades se convierten en resguardos y las jurisdicciones en municipios, teniendo por cabecera, el pueblo más importante.

Evolución cronológica en la población de los pueblos de Ipiales, Pupiales, Gualmatán y Putis de la provincia de los Pasto:

Sobre la fundación de Ipiales: Dice Sergio Elías Ortiz,

(Pasto, 1928) que:

Aunque con bastante razón se tiene por fundadores de la ciudad de Ipiales a los dominicos Andrés de. Zúñiga y Diego de Benavides, quienes hacia 1585 se dice que trasladaron del sitio de Puenes al lugar que hoy ocupa a la mencionada, una información presentada por Juan Caro, administrador del repartimiento de indios de Ipiales al cabildo de la ciudad de Pasto, parece desmentir la primera versión, pues dicho empleado dice que deja "'lerece desmentir la primera versión, pue doce casas que forman el pu vantadas doce casas que forman el pueblo de Ipiales y en ellas 23 mora dores a quienes distribuyó tierras de pan sembrar por mandato de la $\mathrm{Au}$ 58 diencia de Quito y una ermita ". (1616)
Con datos de diferentes documentos se elaboró el cuadro que sigue a continológico los encomende ros, gobernadores y número de indios del pueblo de Ipiales.

\section{IPIALES}

FECHA ENCOMIENDA

GOBERNADOR O CACIQUE

INDIOS

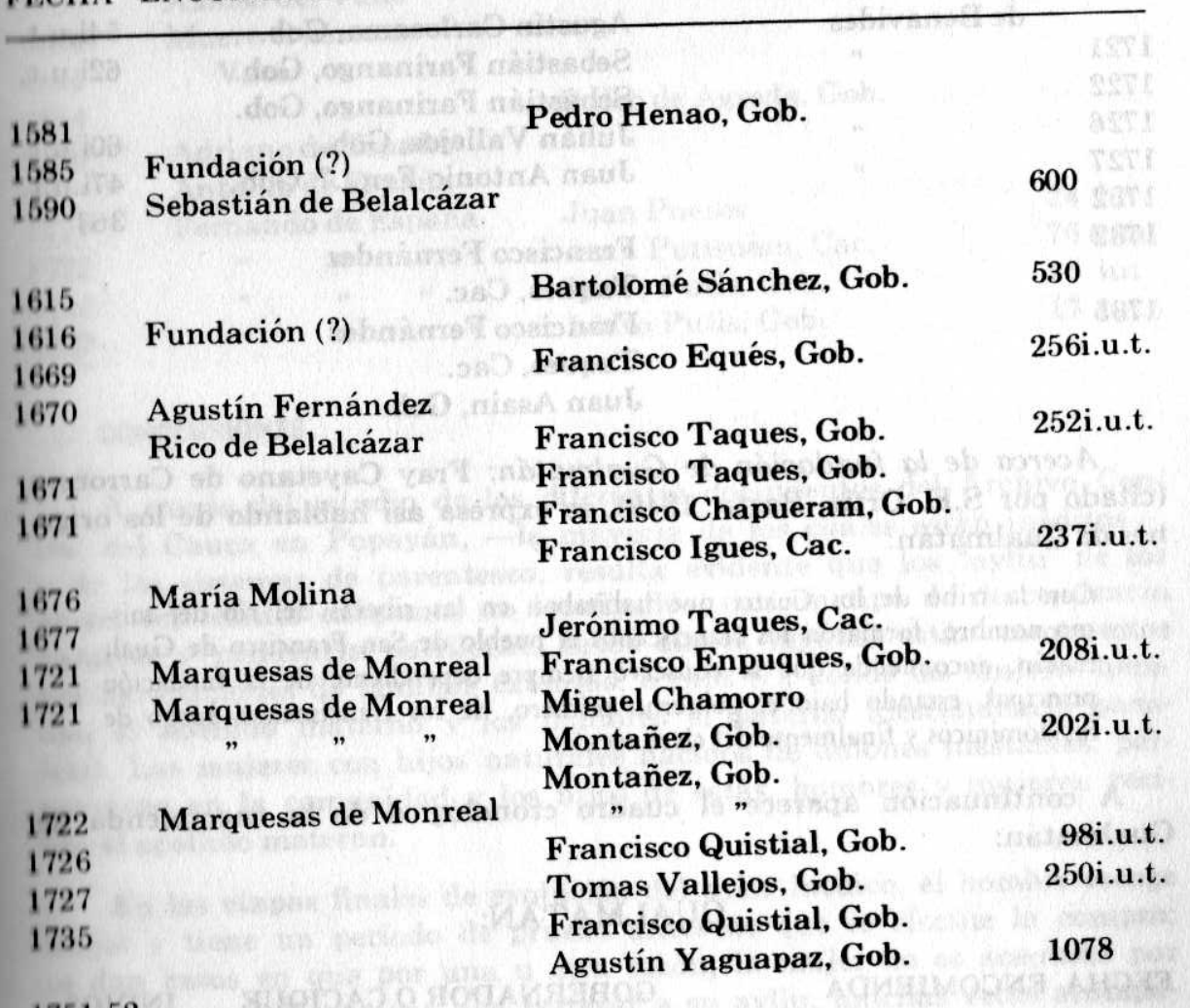

$1751-52$

Sobre la fundación de Pupiales: La fecha probable de fundación de Pupiales es 1575 , pero hasta el momento no consta en ningún documenPupiales es 1575 , pero hasta el momento no condacion fueron enviados a $\mathbf{P u}$ to. En los años sucesivos a su pudiencia de Quito los padres franciscanos piales por orden de la Real Audiencia de Quito misión la toman los dopara adoctrinamiento (1521); posteriormente esta mision la toman los 
PUPIALES
1575 Fundación (?)

1590 Julio Sánchez de Jerez

1721 Cap. Miguel Zambrano

de Benavides

"

1722

1726

1727

1732

1732

1735
1581 Juan Sánchez de Jerez

Fernando Tacuzón, Cac.

Agustín Carlosama, Gob.

Sebastián Farinango, Gob.

Sebastián Farinango, Gob.

Julián Vallejos, Gob.

, Juan Antonio Fen...?, Gob

Francisco Fernández

Taques, Cac.

Francisco Fernández

Taques, Cac.

Juan Asain, Gob.

Acerca de la fundación de Gualmatán: Fray Cayetano de Carrocera (citado por S.E. Ortiz, Pasto, 1949), se expresa así hablando de los orígenes de Gualmatán:

Con la tribu de los Cuatis que habitaban en las riberas del río del mismo nombre, formaron los franciscanos el pueblo de San Francisco de Gual matán, encomienda que se conservó siempre dependiente de la fundación principal, estando bajo el gobierno primero, de los franciscanos, luego de los dominicos y finalmente del clero secular.

A continuación aparece el cuadro cronológico de la encomienda de Gualmatán:

\section{GUALMATAN}

Pedro de Ahumada

Diego del Campo Salazar

Diego de Benavides

Monjas Conceptas

de Pasto

Juan Gualmatán, Gob.

Francisco Gualmatán, Gob.

24 iut

Sebastián Gualmatán, Cac.

Juan Gualmatán, Gob.

Blas Yaesman, Gob.

Blas Yaesnam, Gob. 4i.u.t.

$60 \mathrm{i} . \mathrm{u} . \mathrm{t}$

47i.u.t.

363
Sobre la fundación del pueblo de Putis no tenemos datos; citaré únicamente lo pertinente a la encomienda:

PUTIS:

FECHA ENCOMIENDA

GOBERNADOR O CACIQUE

INDIOS

1590 Alonso del Valle

1609 Muere el Encom.

$\begin{array}{rr}1609 & \text { Muere e } \\ 1611 & \text { Vaca }\end{array}$

1614

1614

1662

?

1721

1722

1726

1729

\section{Adriano de España}

Antonio de España

Fernando de España

$" \quad "$

$" \quad " \quad "$
80

Pedro de Agreda, Gob.

Juan Pueses

Juan Putisnam, Cac.

Isidro Putis, Gob.

Isidro Putis, Gob.
24 iut

76 total

15 iut

17 iut.

\section{CONCLUSIONES}

A través del estudio de los diferentes documentos del Archivo Central del Cauca en Popayán, - la mayoría de los cuales están inéditos-. y de los sistemas de parentesco, resulta evidente que los "ayllu" de los pasto, son clanes exógamos no localizados, con un tipo de descendencia paralela y residencia patrilocal. Estos clanes (ayllus) están compuestos por agrupaciones de familias extensas, o Sibs (?), donde las mujeres heredan el apellido materno y los hombres el paterno (descendencia paralela). Las mujeres con hijos naturales nacidos de uniones inestables, permanecen en la comunidad y los hijos de éstas, hombres y mujeres, reciben el apellido materno.

En las etapas finales de evolución del ayllu incaico, el hombre escoge mujer y tiene un período de prueba antes de que se efectúe la compra; se dan casos en que por una u otra razón, la mujer no es aceptada por su futuro marido, y tiene que regresar a su ayllu, muchas veces acompanada de un hijo. La presencia de mujeres solteras con hijos en los ayllu de los Pasto pudiera obedecer a causas similares de repudio. Entre los Pasto el cacicazgo se hereda de padres a hijos varones mayores, pero en caso de no haberlos, pasa a la hija mayor; si ésta muere, el derecho al cacicazgo le corresponde a un pariente cruzado; las mujeres únicamente tienen derecho a él por "defecto de varon".

Se trataba de un sistema social desconocido y sería interesante en un futuro hacer un estudio comparativo con los ayllus incaicos; por el momento, todo parece indicar en este caso que los españoles del siglo XVIII utilizaron el término ayllu para designar comunidades que tenían semejanzas con las ayllus incaicos, tratándose en realidad de un tipo de organización social poco común. ¿Por qué los cronistas del siglo XVI no mencionan este tipo de organización social entre los Pasto?, únicamente aparece en documentos tardíos. 


\section{BIBLIOGRAFIA}

ACOSTA, Joseph de.

1940

Historia natural y moral de las Indias. Edición de Edmundo O.: Gorman, Fondo de Cultura Económica, 7 libros (Libro VI, Cap. 19). México.

ARROYO, Jaime

1955

\section{BAUDIN, Louis.}

1972

Historia de la gobernación de Popayán. Biblioteca de Autores Colombianos. Bogotá

CABELLO BALBOA, Miguel.

Miscelánea Antártica. Universidad Nal de San Marcos, Fac. de Letras, Inst. de Etnología. Lima

1920 Historia del Perú bajo la dominación de los Incas. (2a parte de su Miscelánea Antártica), Imprenta y Librería San Marti. Lima.

1945 "Verdadera descripción y relación de la Prov de las Esmeraldas, contenida desde el cabo de Pasao hasta la bahía de raldas, contenida desde el cabo de Pasao hasta la bahía de
la Buena Ventura". En: Obras. Vol. I, Editorial Ecuatoriana. Quito.

CIEZA DE LEON, Pedro

1971 La Crónica del Perú. Ministerio de Educación Nal., Instituto de Cultura Hispánica, Editorial ABC. Bogotá

ESCOBAR, Fray Jerónimo de.

1889 Memorial al Real Consejo de Indias de lo que toca a la prov. de Popayán. Anales de Instrucción Pública, Tomo XIV, No. 665. Bogotá

\section{FRIEDE, Juan}

1954 "Errores de la relación que escribió F. Jerónimo de Escobar sobre la Gob. de Popayán". En: Boletín de Historia y antigüedades. Vol. XLI, No. 481-482, Nov-Dic. Bogotá.

\section{GARCES G., Jorge}

1954

"Libro de Cabildos de la ciudad de San Juan de Pasto". En: Revista de Historia. Vol. V. No. 28 a 33, de 1954; Vol. VI, No. 34 a 48 de 1965. Pasto.

\section{GUTIERREZ, Aristides.}

1928 "Tribus y naciones indígenas del tiempo de la conquista". En: Boletín de estudios históricos. Vol. I. Pasto.

\section{HERRERA, Antonio de}

1730 Descripción de las Indias Occidentales. Oficina Real de NiLOPEZ ALVAREZ, Leopoldo.

"Actas del cabildo de la ciudad de San Juan de Pasto". Boletín de Estudios Históricos. Año XII, No. 95-96. Pasto.

"Don Lucas Burbano de Lara". Boletín de Estudios Históricos. Año XII, No. 95-96 y Año XIII, No. 107-108: Pasto.

MARQUEZ, Fidel.

MARQUEZ, Marceliano.

1939

"Contribución al estudio de la geografía por medio de viajes". Boletín de Estudios Históricos. Año XII, No. 95-96. Pasto.

MEIIA Y MEJIA, Justin

1949 "Apuntaciones sobre arqueología del sur de Colombia". En Revista de Historia. Vol. IV. Pasto.

MONTENEGRO, Ulpiano.

1955 Remembranzas. Editorial Voz Católica, Cali.

ORTIZ LOPEZ, Alejandro.

"Documentos del Archivo Central del Cauca". En: Revista de Historia. Abril-Junio de 1942, No. 2 Pasto.

"Para la historia del sur". En: Revista de Historia. No. 1. Pasto.

1944 "Para la historia del sur". En: Revista de Historia. (Doc. No 120), No. 3-4. Pasto.

ORTIZ, S. Elías.

1954

1935

1928

1960

1937

El monasterio de monjas concepcionistas de Pasto. Editorial Cervantes, Pasto.

Estudios sobre lingüistica aborigen de Colombia. Editorial Kelly, Bogotá.

"Las comunidades indígenas de Jamondino y Males". En Idearium, Suplemento No. 1. Pasto.

“Antiguallas Históricas”. En: Boletín de Estudios Históricos. Vol. I, No. 5 y 9 . Pasto.

"Sobre el dominio de los Incas en nuestros territorios del sur". En: Boletín de Historia y Antigüedades. Vol. XLVII Bogotá.

"Sobre la antigua provincia de los Pastos". En: Idearium. Vol I, No. 6. Pasto.

PAZ Y MIÑNO, Luis T 1946

"Lenguas indígenas del Ecuador: La lengua Pasto". En Revista de Historia. Vol. II. Pasto.

PUEYO DEL VAL, Antonio María.

1928 "Visita a Pasto del Oidor Luis de Quiñones". En: Boletín de Estudios Históricos. Vol. II. Pasto.

SARRIA, Juan.

Papeles inéditos. Pupiales, Pup.

ULLOA, Jorge, Juan y Antonio

Noticias secretas de América. 2 partes. Editorial David Barry. Londres. 